\title{
Evaluating Cinchona bark and quinine for treating and preventing malaria
}

\author{
G Gachelin, P Garner, E Ferroni, U Tröhler and I Chalmers \\ Laboratoire SPHere, UMR 7219, CNRS-Université Paris 7, 75205 Paris, Cedex 13, France \\ Corresponding author: G Gachelin. Email: ggachel@club-internet.fr
}

This is the second half of this article. The first half was published in January 2017.

\section{Part 3: Using bark and quinine to prevent malaria in individuals}

Whereas the efficacy of Cinchona bark and quinine for treating intermittent fevers had become widely accepted by the turn of the 18th and 19th centuries, their role in preventing fevers had not been convincingly established. However, as early as 1711, Vallot et al. had reported in the Journal de la santé du roi Louis $X I V$ that he had learned from experience that long term administration of Cinchona bark prevented relapse of fevers. ${ }^{19}$ Long after the King had been declared cured after treatment for intermittent fevers, he was prescribed bark to prevent further attacks.

At that time, people all over Europe lived with mild malaria, and travelers, sailors and soldiers experienced severe fevers in Africa, Central America, and India, where fevers were often named after the place where they had been observed (Coromandel, Guzzarat, Bengali, for example).

The role of armed forces in the development of prophylactic use of Cinchona bark was important. The Count of Bonneval claimed (albeit without any quantitative evidence) that bark had been used with success in 1717 during the siege of Belgrade (quoted in $R e{ }^{81}$ ). However, most historical sources suggest that it was not until the end of the 18th century that European armed forces became aware of the importance of acute malaria for naval and ground operations. ${ }^{82}$ Both of the British naval surgeons sharing the name 'James Lind' wrote about bark for prophylaxis as well as for treatment of intermittent fevers (agues). ${ }^{83,84}$

Alan Magill states in an article on the Centers for Disease Control website that, in 1768, Lind recommended that 'every man receives a daily ration of Cinchona powder'. We have been unable to locate these words in the 1768 edition of 'scurvy' Lind's
'An essay on diseases incidental to Europeans in hot climates, ${ }^{24}$ Lind does note in the book that:

...[U]pon an eclipse of the moon, the English merchants and others who had left off taking the bark, suffered a relapse... and recommends that bark should be taken at the full and change of the moon, as being the seasons most dangerous for an attack or relapse into those intermitting fevers. (Lind, ${ }^{24}$ pp. $81-82$ )

In an Appendix in the 1771 edition of the same book, Lind's ${ }^{83}$ views on bark for prevention is clearer:

[S]trangers in aguish places, and persons subject to agues should take, every other night, two or three teaspoonfuls of tinctura sacra, or a few grains of pilula Rufi, so as to prove gently purgative. For farther prevention, they may take every morning before breakfast, a wine glass of an infusion of bark and orange peel in water; or, what will prove more effectual, a tablespoonful of a strong tincture of the bark in spirits, diluted occasionally with water.

Honigsbaum $^{85}$ has reported that, in 1771 , Lind persuaded the Admiralty to introduce Cinchona bark in wine to crews on 'ships of war on the Guinea station', but the author gives no reference to this and we have been unable to find the quoted passage. Honigsbaum also reports that, in December 1803, Admiral Nelson had directed that 'a dose of Peruvian bark, in a preparation of good wine or spirits' be given to sailors in the morning before going ashore in marshy areas, 'and the same in the evening on his return on board' (again, no reference is given).

Cinchona bark, and quinine soon after, was gradually defined as a prophylactic by the Royal Navy to address medical problems that emerged within a very particular political and military context. The 
Slave Trade $\mathrm{Act}^{86}$ had forbidden the importation of African slaves to British colonies. A similar law was enacted by the USA in 1808 , followed by another in France in 1815. As a result, the British and then the Americans (in 1840) established permanent antislavery squadrons to patrol the African coast. They used rivers to enter deep into the interior, thus operating in highly malarious areas. One historian has estimated that half of all Europeans who arrived in West Africa were dead within a year (Curtain 1998, cited in Mitcham ${ }^{87}$ ).

Cinchona bark had been included in the Navy medicine chest in 1814; the Admiralty began issuing regulations on fevers in 1816; quinine replaced bark in the medicine chest in 1830; and a Royal Navy department of statistics was created in 1831 to gather observations contained in ships' log-books. ${ }^{87}$ There were increasing numbers of case reports of apparently successful prophylactic use of quinine. For example, Thomas Thompson ${ }^{38}$ recorded a personal experience on the West Coast of Africa in 1842:

I determined to commence the experiment in my own person, taking daily one or two full doses of quinine; and although I may with truth say that I was more exposed than any other person to the exciting and predisposing causes of remittent fever... I quite escaped both forms of fever. On being ordered to England...I considered it necessary to reduce gradually the quantum of quinine; and just before arriving home, had left it off entirely: when, strange to say, I was for the first time attacked with tertian ague in England, under which I suffered for some time; and it returned again at the same season, September, the following year.

No comparative clinical trials with and without quinine prophylaxis appear to have been reported until $1847,{ }^{88}$ which saw the publication of the first of two important reports by Alexander Bryson, a British naval surgeon. ${ }^{89,90}$ The first of these contains the following passages:

Cinchona bark and the sulphate of quinine are both extremely useful agents for the prevention of fever; and although it would appear their powers have been considerably underrated...still the numerous instances on record in which they have been successfully employed leave no room to doubt that their more general use upon the station is most urgently required. In the North Star, for example, twenty men and one officer were employed on boat duties at Sierra Leone; they all took wine and bark with the exception of the officer; he was the only person who suffered an attack of fever. Two boats were detached from the Hydra in the year 1844 to examine the Sherbro river; the whole of the men were supplied with bark and wine, and not one of them was taken ill, while the whole of the gig's crew, with the exception of the captain, who were similarly exposed for two days only, without being supplied with either, contracted fever of a dangerous character. Facts like these are not to be mistaken; the previous pages of this report contain many others of nearly equal value. (Bryson ${ }^{89}$, p.218)

Bryson concluded that quinine should be employed as a prophylactic in the Navy instead of bark,

and that its use should be continued, not only while the men were exposed in unhealthy localities, but for at least fourteen days after they returned on board, in order that the antagonistic influence of the medicine might be kept up until the incubation period of the disease had expired. The suggestion was adopted, and the results, upon the whole, are most satisfactory. ${ }^{89}$

The ninth article of the Royal Navy's instructions to physicians specified quinine as the medicine to use to prevent malaria. ${ }^{89}$

[As an aside, Bryson goes on to remark that, given claims that tobacco possessed prophylactic properties, there were 'not any just grounds for believing it to be of the slightest value in this respect' (Bryson, ${ }^{89}$ p.219).]

Bryson's observations also prompted him to guess how quinine might be working.

Although neither bark nor quinine has the power of preventing the germs of fever from lodging in the system, there they may lie dormant for a period of from fourteen to twenty days or even longer, nevertheless, from their peculiar antagonistic properties, they most decidedly have the power in many instances of preventing their development in pyrexial action. Hence the frequently supposed failure of the medicine is undoubtedly to be attributed to its use not having been persisted in for a sufficiently long time after exposure to the exciting causes; namely, throughout the entire probable period of incubation.

It is therefore suggested that it would be advisable not only to administer, daily, one of these febrifuges to men so long as they are exposed to the influence of the land, and the vicissitudes of the weather in open boats, but to continue its use for at least fourteen days after their return on board. As the sulphate of quinine is more certain in its action, infinitely less nauseous than bark, and therefore less objectionable to fastidious people, it should invariably be preferred for exhibition: whether it be given in wine, water, or rum is of no great consequence: the latter will 
generally be the most acceptable to seamen, although they will seldom object to it in wine. (Bryson ${ }^{89}$, p.219)

Based on notes taken out of ships' log books, similar conclusions were reached a few years later by a US Sanitary Commission ${ }^{91}$ based on reports such as the following:

During our stay in the river Lagos, quinine wine was regularly offered to the men, morning and evening - all took it, I believe, except two mid-shipmen and two seamen belonging to the galley. These four persons subsequently each suffered a severe attack of fever. While in the whole force, consisting of upwards of 220 men, there occurred only a few other cases of trifling importance. (Report of Mr. Heath, Surgeon of the Teazer)

Thirty-six men belonging to the Water-Witch were employed in the attack on Lagos; they were in the river four or five days, and, with the exception of three, all took quinine wine while there, and for fourteen days after they left it. Of the whole number, five only were attacked with fever, namely, the three men who did not take the wine, and other two, who most imprudently exposed themselves to the sun, and bathed while much heated by violent exercise. (J. Henderson, Esq, M.D.)

On the morning of the 25th of November, seventyseven men of the ship went up the river Lagos to attack the town. Before starting, every officer and man was ordered to take a glass of quinine wine, and a sufficient quantity was put into the boats to repeat the same at night. All, to the best of my knowledge, took it, with the exception of Mr. D., master's assistant, who rather plumed himself on having escaped taking a dose of physic. This young gentleman, on the 10th of December, just a fortnight after, was seized with a violent attack of remittent fever; and, of the whole number who entered the river, he is the only one who, up to this date (the 7th of January), has been attacked. (F. Stupart, Esq., Surgeon.)

Collation of these reports of dramatically successful protection may have been a mere summing up of positive and negative instances, but this was fairly typical of the approach used routinely throughout the 19th century. ${ }^{92}$ The results of the observations listed on data sheets assembled at the Royal Navy Bureau of Statistics suggested strongly that prophylactic use of quinine was beneficial, provided it was taken before, during and after leaving a malarious area. ${ }^{89,93}$

The observations made were not formal comparisons of sailors who did or did not receive prophylactic quinine. Other practices had been adopted which afforded protection from malaria, even though the role of mosquitoes in causing the disease was unknown. Several military and civilian sources had already shown that the risk of developing malaria could be reduced or avoided by observing some simple rules. ${ }^{94}$ At least as far as the armed forces were concerned, these included not staying on shore at night, staying in closed quarters after sunset, anchoring ships at a distance from the coast (usually one nautical mile), and not swimming in rivers.

In addition, the physical condition of sailors and marines may also have improved as a result of better sanitary conditions aboard, particularly the quality of drinking water, an improvement largely reflecting the opinion that malaria was caused by a water-borne or an air-borne "poison'. 95 Anyway, after 1850, quinine associated with a combination of other antimalarial procedures was adopted as standard procedure in the British and American navies. The mortality in American and British African stations and squadrons, despite a lack of precision in the records, declined abruptly after $1845 .^{87}$

After progress had been made in protecting the health of Royal Navy personnel, Bryson expressed obvious frustration that a proven measure was not yet being used to preserve the crews of some merchant vessels on the coast of Africa. He pointed out that

As these vessels generally carry (for the prevention of scorbutic disease) a supply of lemon juice, which, in consequence of the great abundance of yams and fruit, is nearly if not entirely useless, they ought to carry instead of the lemon juice a sufficiency of quinine wine for the crew, which should be administered in the same manner as in the men-of-war on the station. $^{90}$

The crews of some non-military vessels were protected using prophylactic quinine. For example, in his account of his exploration of the Niger and Tsadda rivers in 1854, William Balfour Baikie reported:

Being now fairly in the river, we commenced giving, morning and evening, to all Europeans on board, two thirds of a glass of quinine wine, which contained about five grains of quinine, believing that this would act as a prophylactic or preventive, while exposed - as everyone must be while in the Delta - to the influence of malaria. ${ }^{96,97}$

By 1861, Report 31 of the US Sanitary Commission $^{91}$ contained material derived from interviews with civilian and military physicians about their practice in malarial areas. The accumulation of personal experiences, whether in America, Africa or 
Asia, led to the conclusion that quinine sulphate - as pills or as quinine wine, in doses of between 3 and 5 grains a day - was effective in preventing malaria. Some of the reports deal with personnel working in plantations in the USA and in Asia, thus confirming the extension of quinine use to malaria-infected agricultural locations. Van Buren, in the name of the Sanitary Committee, wrote:

In conclusion, it may be fairly assumed, even from the
evidence thus imperfectly and hastily collated, that the
power of Quinine as a preventive of miasmatic disease,
is fully established as a medical fact; and that it can be
employed, not only with entire safety, but with the
greatest advantage, even to the saving of life, by healthy
persons exposed to malarial influences. Viewed in the
light of humanity, as well as of economy - both of men
and money - the prevention of disease is of far greater
importance than its cure, and your Committee venture
to express the opinion that intelligent and judicious
action on this important subject at the hands of the
proper authorities would save much sickness and
many valuable lives during the present campaign. ${ }^{91}$

France and French armed forces are surprisingly absent from the debate on quinine as a prophylactic agent. The probable reason was suggested by Laveran $^{98}$ in a critical review of the French attempts to use quinine in this way written after the disastrous Tonkin expedition, during which malaria affected $50 \%$ of French troops. For unknown reasons, the data reported in Laveran's review suggest that quinine used by French physicians appears significantly less effective than that used in the Royal Navy. Laveran $^{98}$ points to inappropriate doses and regimens and to indiscipline. In concluding his paper, he proposes the following controlled trial:

\section{Il y a lieu d'instituer des expériences dans les conditions suivantes. Soit un corps de troupe qui occupe une position insalubre, on le divisera en trois groupes aussi homogènes que possible dont on excluera les hommes ayant déjà eu une fièvre palustre : au premier groupe on donnera une dose quotidienne de quinine (0gr, 20 à $0 g r, 30)$, au deux- ième on prescrira la quinine tous les deux jours $(0 g r, 40$ à $0 \mathrm{gr}, 60)$, le troisième groupe ne prendra pas de quinine et ne prendra rien.}

It sounds sensible to institute experiments under the following conditions. Troops in insalubrious circumstances will be divided into three groups as homogeneous as possible after exclusion of men who have already suffered palustral (marsh) fever: the first group will be given a daily dose of quinine
( 0.2 to $0.3 \mathrm{~g}$ ), the second group will be given quinine ( 0.4 to $0.6 \mathrm{~g}$ ) every other day, the third group will not receive quinine and will not take anything.

The controlled trial proposed by Laveran does not appear to have been carried out either by him or by any other French physicians, although it was done in Italy a few years later (see below).

By the second half of the 19th century, quinine had become an obligatory accompaniment for most Europeans traveling or working in malarial areas. Recognition that a combination of procedures was needed to achieve some control of malaria in certain environments predated the complex array of strategies developed after the origin and transmission of the disease had become understood. It also became clear that, other than in 'disciplined local environments', these measures were unlikely to achieve eradication of malaria. But even in the context of a prison, the effects of prophylactic use of quinine could be disappointing: in a study using alternate allocation of 120 prisoners to 20 grains of quinine on two successive days, or to nothing, no differences between the two groups in subsequent hospital admissions with malaria or length of stay were detected. ${ }^{99}$

\section{Part 4: Efforts to control malaria in populations using mass medication with quinine in the 20th century}

The very end of the 19th century was a turning point in parasitology in general and malariology in particular. Physicians had accepted that a parasite caused malaria and that the parasite could be killed or weakened by quinine. These discoveries provided a rationale for improving the use of quinine for prophylaxis. In addition, new medical measures had been introduced to quantify and monitor malaria by identifying the vectors and searching for parasites in them, and by screening human populations for evidence of infection, including parasites in the blood, and spleen enlargement.

\section{Targeting the parasite: Robert Koch's use of microscopy and quinine to control malaria}

By the 1890s, having discovered and isolated the causative agents of cholera, tuberculosis and anthrax, Robert Koch was prestigious and influential. Since 1891, he had directed the huge Institut für Infektionskrankheiten created for him in Berlin. In the early 1890s, Koch had developed and successfully applied a strategy against cholera focusing on the isolation and elimination of the causative agent, the parasite Vibrio cholerae. By the mid-1890s, 
Koch assumed that the two preconditions for applying this approach in malaria - tracing and destroying the parasite (a Plasmodium) - could equally easily be achieved by microscopic examination of the blood and administering quinine. By analogy, Koch decided that '[t]he experiment (Versuch) to fight malaria according to the same principles [...] absolutely had to be done' (GW, p.456).

Clinical experimentation, with a protocol and precise numerical statements, was not Koch's forte, and it has been something of a struggle to piece together, using the online edition of Koch's Collected Works (Gesammelte Werke, GW), relevant information from over a 100 pages of his letters, reports and other documents about malaria written between 1898 and 1908. Koch R. Gesammelte Werke, Berlin 1912. Page numbers that follow in this section refer to volumes 2.1 or 2.2, respectively of this edition, see http://edoc.rki.de/browsing/rki rk (last checked 18 January 2017).

Koch's intensive involvement in attempts to control malaria appear to have begun in 1898, when he asked his administrative superior, the Prussian minister of religious, education and medical affairs, for money to fund an expedition to Italy and the Dutch Indies (GW, pp.883-887). He started off with a campaign in the Tuscan maremma around Grosseto, together with an Italian colleague, Professor Gosio. Gosio had hitherto fostered physical antimalarial measures directed against the vector - petroleum on marshes, draining stagnant water, and mosquito nets - which had been promoted by the Italians and the British. Koch's ${ }^{100}$ work in Italy appears to have continued until at least 1903, and although some letters about it were published, these do not provide any basis for strong inferences about the success of Koch's malaria control methods there.

Soon after starting his work in Italy, 'an extraordinarily lucky opportunity' presented itself to Koch to perform a further 'experiment' in New Guinea. He found in New Guinea an almost untouched, beautiful and luxuriant country, yet infested by malaria (p.440). This meant that he could start his experiment from scratch. Koch's stay in New Guinea from 29 December 1899 till 8 August 1900 proved decisive for his future statements about the control of malaria. His experimental community was the German plantation site of Stephansort, ${ }^{101}$ which had 734 inhabitants and two 'hospital houses' (one for the roughly five dozen Europeans [GW p.404], the other for the natives).

First, the blood of all 734 inhabitants was examined for parasites. The population was submissive, and small gifts were given to the children to secure their compliance (p.414). Parasites were found in the blood of 157 of the 734 inhabitants (GW, pp.404-411, 443), and they were treated immediately with quinine. Koch stipulated that patients were to be given $1 \mathrm{~g}$ of quinine daily until the malaria parasite had disappeared from their blood, then, after an interval of seven days, a gram of quinine was to be given on each of two days, followed by another seven-day interval, and so on, for at least two months (p.411). Upon re-examination two months later, 'only a very small number' remained carriers of parasites, and 'fresh cases were hardly observed thereafter' (p.895).

This 'experiment' was deemed by Koch to have been 'perfectly successful' (p.443), and he suggested that that the treatment principles were also applicable for prophylaxis (p.413).

Newcomers to New Guinea were usually very susceptible to malaria: $47.4 \%$ of recruited workers from the Gardner Islands fell ill soon after their arrival at Stephansort. They were treated immediately and cured. Those who had remained healthy received quinine prophylactically, and Koch reported that 'not one of them got malaria' (p.413). In February 1900 , a ship carrying workers recruited from the island of Ambon arrived.

\section{About half of them were given quinine prophylactic- ally, the other half was not; the first group remained healthy, whilst all of the second [group] fell ill with malaria, except a woman. They were all treated at Stephansort, and soon recovered'. (GW p.413; Koch $^{101}$ )}

The three members of Koch's expedition used quinine prophylaxis regularly. None had contracted malaria after four months (p.413), although Koch noted that prophylaxis with quinine was 'somewhat tiresome' and 'disagreeable' (p.414).

In June 1900, Koch insisted that this success was not accidental since there had been very few new cases in Stephansort, even during the rainy season - six in May, one in June. ${ }^{101}$ Since the experiment had been conducted over a period of six months, he deemed the result to be 'unequivocal' (p.416). 'Our experiment at Stephansort proves that our procedure also works in tropical climates, and it works quickly' (p.428).

What was the evidence for Koch's strong claim? From Stephansort, he reported one prospective comparative trial and a retrospective comparison, yet both were presented in very vague numerical terms: the number of persons observed was not stated, and the results were given using terms such as 'all' and 'none' or as 'decrease by over $50 \%$ '. This imprecision may be well due to the fact that people were hard to register and follow-up in these colonies, with rapidly fluctuating migrant populations. 
Koch's assertions about the success of his approach $^{102}$ depended rather on the logic of focusing on the parasite and not the vector.

My procedure is something completely different. I have to stress this explicitly. The "quinineprophylaxis" wants to prevent the infection of men as such. My procedure is directed to towards the parasites in the infected men. It aims at healing all patients (p.428). [...] Physical measures and desiccation of marshes may be done, "but by themselves they will achieve nothing against malaria". (p.446)

As the mosquitos would persist, Koch's aim was to eliminate the parasite, and this had become more possible on a mass scale because quinine had by then become less expensive (pp.427-428).

Koch listened to criticism. Although he debated questions of dosage and presentation of quinine (pp.429-430), however, he stuck to what he referred to as 'my rather conspicuous experience' (p.432). He was aware that his results at Stephansort might be coincidental and/or might be true only because this was a small local community. He replied to these criticisms by observing what happened over time, and by having his method applied in Italy and East Africa where thousands of people were examined and treated. ${ }^{103} \mathrm{He}$ also suggested, however, that such experiments be conducted in Germany, where longer-term follow-up would be easier (p.416). Later that year, he was able to further document the success of his approach by publishing tables of incidence of malaria among the military in Northern Germany. It had decreased from 54.9 per 1000 in 1896 to 0.45 per 1000 in 1897 (p.444).

In October and November 1902, in two letters to his administrative superior, the Prussian minister, Koch reported again on his Stephansort experiment and the further successful applications of his procedure, at his instigation, in North-West Germany; on the Croatian coast; and in German East Africa (Tanganyika). At the first site, there had been no outbreak of malaria during dyke building works at Wilhelmshaven; at Brioni (Croatia) malaria had been eradicated; and in Dar es salam, 'the number of those ill with malaria had decreased by more than 50\%' (p.895).

Koch emphasised in his letters that his approach had been intentionally restricted to microscopy and quinine to prove that this approach was capable of eliminating malaria in a variety of climatic and social circumstances (p.896). In his view, physical antimalarial measures were at best only 'a support for my procedure' (p.896).
In 1903, Koch $^{101}$ concluded robustly:

...By this experiment it is proved that malaria can be fought by the same principles as cholera. Of course one may also use other measures to restrict malaria as, for instance, the elimination of the mosquitos recommended by Ross or the protection against mosquito bites with bed nets as tried out in Italy". (GW, p.457)

In 1908, he added that nets might be tried in the colonies 'in order to prevent the possible reproach of an omission' (p.897).

Ronald Ross's book The Prevention of Malaria ${ }^{104}$ was published in the year Koch died. It contained contributions by authors from all parts of the world. Koch's method was initiated by Ollwig in Dar es salam in 1901-1903 ${ }^{103}$ and appears to have continued at least until $1914,{ }^{105}$ and was reported as having been 'successful in so far as it has at least considerably reduced the incidence of malaria'. Yet, in the longer term, Koch's approach did not seem to have worked consistently. In a 1913 paper, Manteufel, a German working in Dar es salam, showed 'from carefully kept records,[...] not subject to the usual errors of such compilations, ${ }^{105}$ that, despite continued administration of quinine between 1903/04 and 1912/13, both the incidence and the mortality of malaria had increased noticeably among Europeans and the native population. ${ }^{107}$

References to the Dar es salam experience in Ross's book and elsewhere, and Manteufel's statistics, prompted AJ Orenstein - whose principal duty in Dar es salam had been to institute a campaign against malaria - to report his test of Koch's theory that malaria could be eradicated by attacking the parasite within the human host. ${ }^{105}$ This was a replication of Koch's Stephansort experiment which involved treating all infected students in the Dar es salam Trade School according to Koch's regimen and then comparing the infection rates up to nine months after quinine treatment. More than one-third of the students became reinfected during the Christmas holidays. ${ }^{105}$

In parallel, Orenstein did the same test with 150 natives (adults and children), chosen at random, living near a mosquito-breeding pond, before and after a five-month period during which the pond had been cleaned and treated with phenol at 10-day intervals. The climatic conditions had remained practically constant, and the blood tests were performed in both studies by the same person "who had no idea whatsoever of the purpose or nature of the experiment'. The decrease in infection rate was only $13.9 \%$ in the schoolboys and about $20 \%$ in the native population. ${ }^{105}$ 
Orenstein concluded that Koch's prophylaxis should not be 'condemned as useless. It may have a certain degree of usefulness, but it is, much to my regret, a very insignificant degree when applied to a permanent community of considerable size in a country where anophelines [...] abound', and where, in addition, immigration continuously introduces carriers. ${ }^{105,106}$

\section{Angelo Celli's use of mass medication with quinine to control malaria}

Italy provides the earliest and best example of formal, state-organised quinine prophylaxis, based on the then recent scientific achievements. The Italian government passed a law in 1902 establishing a state monopoly for quinine trade and distribution so the drug became widely and regularly distributed among industrial workers and children. ${ }^{108}$ The Torino quinine factory, which was placed under the control of the Ministry of Finance, produced 60 tons of quinine a year (a further 27 tons were imported). The drug was sold at fixed prices and distributed either through municipal dispensaries or through charities. Children were particularly targeted and special preparations were used for them (quinine in sweets or in syrups). About 10,000 specialised physicians (medici condotti) were responsible for malaria surveys and treatment, and the Directorate of Public Health was in charge of malaria sanatoria and mobile and static dispensaries. ${ }^{108}$

The earliest comparative trial of quinine used prophylactically in populations appears to have been that organised by Angelo Celli. Celli had previously reported on his controlled evaluation of physical measures to protect Italian railway workers and their homes from mosquitos. ${ }^{109-111}$ In 1903, he reported an evaluation of the effects of prophylactic use of quinine in a number of Italian cities: ${ }^{12}$

the first year we treated part of the population with quinine prophylaxis, leaving the rest as control. The year after, thanks to the results on the effectiveness of the treatment, no prejudice or diffidence from the population will emerge and this prophylaxis will reach popular consent.

Celli's ${ }^{112}$ report is not clear about how the allocation to prophylaxis or control was made, and no comparative statistics were presented in his report.

In the second part of a paper devoted to malaria in Italy in 1902, Celli describes a large-scale experiment on malaria prophylaxis using quinine. ${ }^{112}$ Following an initial experiment conducted in 1901 which had given promising results, the intervention was extended in 1902 to 16 rural (for example, Agro romano) and urban (for example, Milano and Mantova) malarial areas, mostly in northern and central Italy, including the Pontine Marshes and Ostia. Prophylactic quinine was withheld from part of the population at each location as controls. The intervention was used in two different ways: either continuous (daily) administration of quinine (in most of the areas), or discontinuous (weekly) administration of quinine. Free quinine pills were distributed to the rural populations by physicians. The trials were conducted from May to December, depending on the locations. However, physicians did not use a standard protocol, which makes it difficult to compare different local trials.

The Table summarising the data in Celli's ${ }^{112}$ report can be analysed in two ways. By summing up the results of all the studies, it appears that, in the context of daily administration of quinine, 923 people received quinine every day (25-30 centigram) and $44(4.4 \%)$ of them developed malaria. In the control groups, the proportion of people who became ill varied between $12 \%$ and $82 \%$. Of 2133 people who received from $1-2 \mathrm{~g}$ per week to $3 \mathrm{~g}$ every nine days, 191 (about $10 \%$ ) became ill compared with between $40 \%$ and $80 \%$ in the control groups. Out of a total of 3055 people treated daily or weekly, only $235(7.7 \%)$ became ill or experienced a relapse compared with $12 \%$ to $82 \%$ among controls. The results suggest a protective effect of quinine, particularly daily administration. However, the wide range of malaria incidence among untreated patients precludes firm conclusions.

The second way of reading the data involves comparing the values obtained within each location. This reveals marked variations in the apparent efficacy of quinine prophylaxis and suggests that intermittent administration is less effective than daily administration. Celli does not discuss the variations, nor does he describe the characteristics of the treated and untreated populations, or how they were chosen. In the same article, he reports prophylaxis using a combination of salts of iron, arsenic and quinine, promoted by industry and administered in 1901 to railway workers in Foggia, south Italy. Daily administration of quinine $(0.15 \mathrm{~g})$, arsenic and iron was used in 54 individuals, $8(14.8 \%)$ of whom became ill. Weekly administration of quinine $(1 \mathrm{~g})$, arsenic and iron (one spoon daily, $0.01 \mathrm{~g})$ was used in 52 individuals, $10(19.2 \%)$ of whom became ill. Celli concluded that combined treatment was no more effective or better tolerated (but was more expensive) than quinine alone.

Celli's study is one of the first quantitative attempts to examine, at a population level, 
the prophylactic use of quinine. Despite the obvious limitations of the approach, the message was clear: quinine has a significant prophylactic activity when administered daily to populations exposed to the parasite. The earlier conclusion reached by Navy physicians was not only confirmed but extended. Thus it seemed that an antimalaria public health policy should, at least in part, include systematic administration of antimalarial drugs.

However, it rapidly became apparent to Italian malariologists that quinine-based prophylaxis of malaria was not easy to scale up, and in the end, this strategy failed to control the disease. It certainly helped, but not to the extent that had been hoped. It had met with a number of unexpected difficulties and limitations. Snowden ${ }^{113}$ describes the ambiguities of the quinine-based campaign against malaria in Italy and the multiple economic, societal and political reasons for its failure in many areas. People did not take the drug as frequently as they needed to, and some refused to take it. Reinfection was the rule. The side effects of quinine (nausea and tinnitus) are not mentioned in the trials, but they may have contributed to the rejection of quinine prophylaxis by some within the population. The diffuse resistance of the general population to quinine prophylaxis is not documented in the Italian medical writings, but it is in a later report by the League of Nations. ${ }^{5}$

This factor had been emphasised in 1914 in a review of quinine prophylaxis by a senior surgeon in the United States Public Health Service. ${ }^{88} \mathrm{He}$ contrasted Celli's experience in towns and villages with that in the penal colony in Castiadas, Sardinia, where quinine had been given under orders. During 1904, 1905 and 1906, no prophylactic quinine had been given, and $76 \%$ of the prison population developed malaria. After four years of prophylaxis, the percentage affected in 1911 was just $5 \%$.

The important additional factor that needed to be taken into account was thus the influence of social factors on the effectiveness of quinine prophylaxis. ${ }^{5}$ Some kind of social organisation strongly supporting antimalaria campaigns was needed for quinine prophylaxis to become effective: that was the case among armed forces and railway workers, then characterised as 'disciplined populations', as were mine workers in Spain ${ }^{114}$ and rice-workers in Italy. ${ }^{113}$

In the latter two cases, efficient quinine prophylaxis relied on the existence, or on the construction, of a strong social organisation of workers, which in turn resulted in trade unions. 'Civilian societies' had to be completely convinced that it was sufficiently in their interests to take quinine regularly. The affected populations had thus to be educated: the place of individual and collective responsibility was the lesson drawn from attempts at malaria prophylaxis. In summary, efficient campaigns of quinine prophylaxis at the population level were those which had been 'unionised', 'militarised' and 'politicised'. 8,113

\section{League of Nations assessment of mass medication with synthetic antimalarial drugs}

Mass medication with quinine and with the new synthetic antimalarial drugs was attempted in the 1930s in French Indochina, ${ }^{115}$ the Malay States, ${ }^{68}$ Algeria ${ }^{116}$ and Italy, ${ }^{76}$ among other places. ${ }^{75}$ Reviewing the experience, the Malaria Commission of the League of Nations observed (p.995):

In only a few of the experiments were there control groups or villages kept wholly without treatment [prophylaxis]. As previously, lack of adherence to the regimens prescribed meant that early promise was not sustained. Owing to the natural variations occurring from season to season in the density of the anopheline fauna, as well as the disease itself, the results of experiments without controls can only be accepted with caution.

The Commission concluded its report with some practical suggestions for treatment and prophylaxis (pp.1012-1016). With regard to the treatment of individuals, the Commission referred to the desirability of microscopic examination of the blood, and that mass treatment with quinine or atebrine should be accompanied or followed by plasmoquine to reduce the risk of relapses. The report notes that there were large malarial areas, where mass treatment was impossible for financial or other reasons. The conclusions with respect to mass drug prophylaxis were even more sobering. Without 'disciplined communities under strict supervision' mass drug prophylaxis was highly unlikely to be useful. Indeed, experience had shown that the eradication of malaria by treatment and prophylaxis with the drugs then available was 'practically impossible'.

With regard to the choice among the several antimalarial drugs then available for curative or prophylactic mass treatment, the Commission ranked quinine first because of its clinical effectiveness, almost complete absence of serious toxicity, and the widespread knowledge of its use and dosage. Indeed, quinine remained unchallenged for a further half century, when controlled trials showed that artemether and artenusate - which had also been derived from plants and used to treat fever ${ }^{117}$ - were shown to be superior to quinine in treating severe malaria. ${ }^{118,119}$ 


\section{In summary}

The sometimes dramatic results of treatment of intermittent fevers with Cinchona bark dates back to the 17th century, and bark was used effectively throughout the 18th century and beginning of the 19th century. Quinine - the active principle in bark - was isolated at the end of the second decade of the 19th century, and because it was more palatable and could be more confidently dosed than bark, it was widely adopted during the second half of the 19 th century and the 20th century.

In addition to the clear effectiveness of bark and quinine in treating intermittent fevers, their prophylactic administration also resulted in dramatically effective protection of individuals against these fevers. The therapeutic and preventive effectiveness of bark and quinine in individuals was obvious without carefully controlled trials and was identified and adopted a century before the cause of malaria and the cycle of Plasmodium had been elucidated.

Although the important role of quinine in treating and preventing malaria in individuals became clear during the 19th century, differences between the effects of different quinine alkaloids, and between quinine and bark and other antimalarial drugs were not dramatic. This led to a recognition that formally planned experiments were required to obtain trustworthy results. Methodological ground rules began to emerge during the 1920s and 1930s, particularly in India and the Malay states, that comparison groups should be generated by alternation and that groups of sufficient size were required to obtain reliable evidence of treatment differences on substantive treatment outcomes.

Although the use of quinine to treat and prevent malaria in individuals was dramatically successful, research in Italy in particular showed that scaling this up to prevent malaria in populations was unsuccessful, both because of poor compliance with selfmedication, and because of the frequency of reinfection. This general conclusion applied except in circumstances - prisons and navies, for example - in which community self-discipline could be assured.

It was not until the 21 st century that any alternative antimalarial drugs were shown in well designed, large controlled trials to be superior to quinine, and then only in severe malaria. The enduring beneficial effects of Cinchona bark and quinine over three and a half centuries are remarkable.

\section{Declarations}

Competing interests: None declared.

Funding: None declared.

Ethics approval: Not applicable.
Guarantor: GG

Contributorship: GG, EF, UT and IC, were responsible for researching and reviewing sources in French, Italian, German and English, respectively. PG ensured that the article was malariologically accurate. All authors agreed the final version of the article.

Acknowledgements: The authors thank Nor Asiah, Estela Dukan, Christoph Gradmann, Ronald Henry, Su May Liew, and Holger Maehle for providing information; Jan Peter Verhave for information about Nicolaas Swellengrebel; Mohamed Asyraf Bin Noh for help in locating relevant material in Kuala Lumpur; and Nicholas White for helpful comments on an earlier draft.

Provenance:: Invited article from the James Lind Library.

\section{References}

19. Vallot A, D'Aquin A and Fagon GC. Journal de la santé du roi Louis XIV de 1647 à 1711. Paris: Auguste Durand (manuscript completed by Fagon dated 1711, published in 1862). See http://gallica.bnf.fr/ark:/12148/ bpt6k203302w.r=Journal $\% 20 \mathrm{de} \% 201 \mathrm{a} \% 20$ sant $\%$ C3\%A9\%20du\%20roi\%20Louis\%20XIV\%20de\% 20l'ann $\%$ C3\%A9e (last checked 13 November 2016).

24. Lind J. An Essay on Diseases Incidental to Europeans in Hot Climates. London: Becket and De Hondt, 1768.

68. Field JW, Niven JC and Hodgkin EP. The prevention of malaria in the field by the use of quinine and atebrine. Bull Health Org League Nations 1937; 6: 236-290.

75. Malaria Commission. The treatment of malaria: study of synthetic drugs, as compared with quinine, in the therapeutics and prophylaxis of malaria. Bull Health Org League Nations 1937; 6: 897-1033.

76. Bastianelli G, Mosna E and Canalis A. Prevention and treatment of malaria by synthetic drugs. Bull Health Org League Nations 1937; 6: 822-891.

81. Rey HJ. Analyse critique du traité des maladies des gens de mer de PM Gonzalez [Critical discussion of the treatise on diseases of seamen by PM Gonzalez] (Cadix, 1805). Arch Med Naval 1871; 15202.

82. Osborne MA. The geographical imperative in nineteenth century French medicine. Medical History 44, s20, Medical History in Historical Perspective, 2000: $31-50$.

83. Lind J. An Essay on Diseases Incidental to Europeans in Hot Climates. London: Becket and De Hondt, 1771.

84. Lind J. A Treatise on the Putrid and Remitting Marsh Fever which Raged in Bengal in the Year 1762. Edinburgh: C Elliot, 1776.

85. Honigsbaum M. The Fever Trail. London: Macmillan, 2001, p.52.

86. Abolition of trade slavery act (25 March 1807) http:// www.nationalarchives.gov.uk/.

87. Mitcham JC. Patrolling the White Man's Grave: the impact of disease on Anglo-American naval operations against the slave trade, 1841-1862. The Northern Mariner 2010; 20: 37-56.

88. Carter HR. Quinine prophylaxis for malaria. Publ Health Rep 1914; 20: 741-749. 
89. Bryson A. Report on the Climate and the Principal Diseases of the African Station. London: Samuel Highley, 1847.

90. Bryson A. Navy medical report no. XV. On the prophylactic influence of quinine. Med Times Gazette 1854; 8: 6-7.

91. US Sanitary Commission. Committee Appointed by Resolution of the Sanitary Commission to Prepare a Paper on the Use of Quinine as a Prophylactic against Malarious Diseases. Report No. 31. New York: Wm. C Bryant \& Co., Printers, 1861.

92. Jorland G, Opinel A and Weisz G. Body Counts: Medical Quantification in Historical and Sociological Perspectives. Montreal: McGill-Queens University Press, 2005.

93. McShane C. Medical statistical returns of the African station. In: Statistical Report of the Health of the Royal Navy for the Year 1856. London: House of Commons, 1856: 82-83.

94. Montfalcon JB. Histoire médicale des marais et traité des fièvres intermittentes. [Medical history of marshes and treatise of intermittent fevers]. 2ème edn. Paris: Béchet Jeune, 1826.

95. Watt J. The health of seamen in anti-slavery squadrons. Mariner's Mirror 2002; LXXXVIII: 69-79.

96. Baikie WB. Narrative of an Exploring Voyage up the Rivers Kwo'ra and Binue. London: John Murray, 1856, p.34.

97. McConnaha W. William Balfour Baikie and the prevention of malaria. J R Nav Med Serv 2007; 93: 27-32.

98. Laveran A. De l'emploi préventif de la quinine contre le paludisme. Revue d'hygiène et de police sanitaire. [About the preventive usage of quinine against malaria]. 1896; 18: 223-240.

99. Waters EE. Malaria as seen in the Andamans penal settlement. Lancet 1903; 1: 1657-1662.

100. Koch R. Die Bekämfung der Malaria [Fighting malaria]. Ztschr F Hyg U Infektionskrankh 1903; 43: $1-4$.

101. Koch R. Vierter Bericht über die Thätigkeit der Malaria-Expedition, die Monate März und April 1900 umfassend [Fourth report on the activity of the malaria expedition, comprising the months of March and April 1900]. Deutsche medicinische Wochenschrift 1900; 25: 397-398.

102. Koch R. Halben lecture. 'Address on malaria to the congress at Eastbourne.' In: Koch, Gesammelte Werke 1901; 2: 448-455.

103. Ollwig H. Die Bekämfung der Malaria [Fighting malaria]. Ztschr F Hyg U Infektionskrankh 1903; 43: 133-155.

104. Ross R. The Prevention of Malaria. New York: Dutton, 1910.

105. Orenstein AJ. Contribution to the study of the value of quininization in the eradication of malaria. JAMA 1914; 63: 1931-1933, p. 1932.
106. Ewers WH. Robert Koch, his work in New Guinea and his contribution to malariology. Papua New Guinea Med J 1972; 15(2): 117-124.

107. Manteufel P. 12 Jahre Malariabekämfung [12 years of fight against malaria]. Ztschr $F$ Hyg $U$ Infektionskrankh 1913; 53: 76-81.

108. Corbellini G. Italian antimalarial legislation, with particular reference to the State's quinine laws. Parassitologia 2003; 45: 155.

109. Celli A. La nuova profilassi della malaria nel Lazio [The new prophylaxis against malaria in Lazio]. Supplemento al Policlinico 1900; 6: 1601-1606.

110. Celli A. The new prophylaxis against malaria in Lazio. Lancet 1900; 156: 1603-1606.

111. Ferroni E, Jefferson T and Gachelin G. Angelo Celli and research on the prevention of malaria in Italy a century ago. JLL Bulletin: Commentaries on the history of treatment evaluation, 2011. See www.jameslindlibrary.org/articles/angelo-celli-and-research-onthe-prevention-of-malaria-in-italy-a-century-ago/ (last checked 13 November 2016).

112. Celli A. La malaria in Italia durante il 1902. Parte II: Profilassi della malaria [Malaria in Italy during the year 1902. Part 2 : prophylaxis of malaria]. Annali di Igiene Sperimentale 1903; 13: 322-343.

113. Snowden FM. The Conquest of Malaria: Italy (19001962). New Haven, CT: Yale University Press, 2006.

114. Rodríguez-Ocaña E. The birth of the anti-malaria campaign in Spain during the first 30 years of the 20th century: scientific and social aspects. Parassitologia 2005; 47: 371-377.

115. Robin L and Van-Huan T. Essais comparés de prophylaxie médicamenteuse en région hyperendémique par la praequine et la quinine ou la quinacrine [Comparative trials of anti-malarial drug prophylaxis in a hyperendemic area with præquine, associated with quinine or quinacrine]. Bulletin de la Société de Pathologie exotique 1935; 28: 650-658.

116. Parrot A, Catanei A, Ambialet R and Clastrier J. Comparative experiments in mass prophylaxis of malaria by means of quinine and synthetic drugs (quinacrine and praequine). Bull Health Org League Nations 1937; 6: 685-765.

117. $\mathrm{Tu} \mathrm{Y}$. The discovery of artemisinin (qinghaosu) and gifts from Chinese medicine. Nat Med 2011; 17: 1217-1220.

118. Sinclair D, Donegan S, Isba $\mathrm{R}$ and Lalloo DG. Artesunate versus quinine for treating severe malaria. Cochr Database Syst Rev 2012; Issue 6. Art. No.: CD005967.

119. Esu E, Effa EE, Opie ON, Uwaoma A and Meremikwu MM. Artemether for severe malaria. Cochr Database Syst Rev 2014; Issue 9. Art. No.: CD010678. 